\title{
Modeling Episode-Based Payments for Cancer Using Commercial Claims Data
}

\author{
Michael Polson, PharmD, MS; Todd Lord, PharmD, AE-C, CDOE; Themmi Evangelatos, PharmD, MSBA; \\ Anne Kangethe, PharmD, MPH, PhD; Lindsay C. Speicher, JD; Servi Barrientos, BS; \\ and Christopher Zacker, RPh, PhD
}

\begin{abstract}
BACKGROUND: Innovative health care reimbursement models are gaining attention as a way to move away from a payment system that rewards quantity of service over quality of care. One such alternative payment model is episode-based payment, such as the 0ncology Care Model (OCM) being piloted by the Center for Medicare \& Medicaid Innovation.

OBJECTIVE: To adapt the OCM methodology to a commercially insured population to understand the challenges and potential implications of implementing an episode-based payment model in a commercial health plan.

METHODS: Administrative claims databases from 3 regional commercial health plans were used to identify continually eligible patients (aged $\geq 18$ years) with breast cancer, lung cancer, melanoma, or chronic myelogenous leukemia (CML). Episode triggers were identified using the $\mathrm{OCM}$ methodology. In calculating the episode-based payments, adjustments to the 0CM methodology were necessary to adapt the methodology to a commercial population, since not all Medicare data elements used in the 0CM algorithm are available in commercial claims data.
\end{abstract}

RESULTS: The adapted OCM-like model was applied to data from 39,967 patients with 1 of 4 cancer types. Approximately $13 \%$ of patients had at least 1 episode per year and the average number of episodes per patient per year for patients with at least 1 episode ranged from 1.42 for patients with melanoma to 1.94 for patients with CML. The percentage of total annual costs included in episodes was $49 \%, 60 \%, 34 \%$, and $52 \%$ for breast cancer, lung cancer, melanoma, and CML, respectively.

CONCLUSIONS: As health care financing shifts to alternative payment models, insurers may look to adopt episode-based payments for oncology, similar to the OCM. This study shows that implementing an OCM-like model in a commercial health plan is feasible but will require adjustments to the OCM algorithm to make it implementable and applicable to populations beyond Medicare.

J Manag Care Spec Pharm. 2019;25(2):235-45

Copyright @ 2019, Academy of Managed Care Pharmacy. All rights reserved.

\section{What is already known about this subject}

Innovative health care reimbursement models are trending as a way to move away from payment systems that incentivize quantity of service over quality of care.

The Oncology Care Model (OCM), an episode-based payment model, has been piloted in Medicare.

\section{What this study adds}

Using administrative claims data, this study provides insight into the implications of implementing an episode-based model, based loosely on OCM methodology, at a commercial plan.

This study provides an assessment of the required adjustments that can make the OCM algorithm applicable and valuable to populations beyond Medicare.

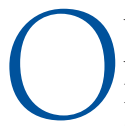
ver 1.6 million people are diagnosed with cancer each year in the United States, and the cost of treating these patients is steadily increasing, with projected growth of treatment costs between $7.5 \%$ and $10.5 \%$ through $2020{ }^{1,2}$ Given this rapid increase in costs, refining the payment system is a growing priority. Innovative health care reimbursement models aimed at shifting focus from the quantity of services provided to the quality of outcomes achieved have been implemented by several payers, including the Anthem/WellPoint Cancer Care Quality Program, Aetna's medical home system, and the Center for Medicare \& Medicaid Innovation (CMS Innovation Center) Oncology Care Model (OCM). ${ }^{3}$ Due to the prevalence of cancer in elderly patients, Medicare pays for a large share of oncologic care. ${ }^{4}$ To address rising costs of care, the CMS Innovation Center implemented the OCM, an episode-based payment pilot program that combines fee-forservice, per-beneficiary-per month payments (i.e., monthly enhanced oncology services), and performance-based incentives. ${ }^{5}$ In the OCM, an episode is defined as a 6 -month period that begins with a qualifying chemotherapy claim. ${ }^{5}$ Episodebased payment arrangements aim to reduce unnecessary care, avoidable hospitalizations, complications of treatment, and inefficient resource use. ${ }^{5,6}$ While the OCM is still in its infancy, other episode-of-care payment initiatives, such as the UnitedHealthcare episode-based payment program have been studied and demonstrate the potential benefits of an episodebased payment model. ${ }^{7}$

Episode-based payment mechanisms have been promoted as a means to reduce incentives to overuse unnecessary health care services and improve efficiency by optimizing care coordination. ${ }^{5,6,8,9}$ By including quality metrics, episode-based payments are intended to promote greater patient focus and 
avoid incentives for clinicians to undertreat. ${ }^{10,11}$ In addition, episode-based payments give health care providers the flexibility to decide the level and types of services to be delivered, rather than constrain their decision making by fee codes and utilization management tools. ${ }^{12}$ By removing the need to adhere to a "correct" treatment, physicians are given freedom to choose the most appropriate care for individual patients.

In February 2018, the CMS Innovation Center released the first annual report evaluating the OCM. The report indicated that baseline analyses provided a strong foundation for future evaluation of OCM impact. ${ }^{13}$ Thus, interest is anticipated to develop among commercial insurers for implementing similar payment models for commercially insured patients, since 11\% of the health care spend for commercial insurers is accounted for by oncologic care provided to less than $1 \%$ of covered lives. ${ }^{4}$ While episode-based payment models similar to the OCM present opportunities for commercial payers, they also present a significant challenge. ${ }^{4}$ Defining episodes and quantifying episode payments will require significant data analytic capabilities, development of appropriate quality and performance measures, and alignment of incentives for payers and providers, which will challenge even the most sophisticated insurers. To date, research on the OCM has focused on Medicare plans and has not assessed its implementation by commercial health plans. ${ }^{14}$

The goals of this project were to (a) approximate the OCM algorithm and methodology to commercial claims data; (b) understand how episode-based payments for selected cancer types may be affected by episode-based payments; and (c) evaluate the feasibility and challenges of implementing an episodebased payment model in a commercially insured population.

\section{Methods}

Development of the model involved 2 phases. First, a retrospective study of 4 cancers (breast cancer, lung cancer, melanoma, and chronic myelogenous leukemia [CML]) was conducted to define episodes of care and establish baseline spending measures. These 4 tumor types were chosen to represent a mix of cancers in terms of prevalence, treatment patterns, innovation, and solid and hematologic tumors. Second, an episode-based model was developed, with consideration of the data limitations of commercial claims data.

\section{Phase 1: Retrospective Claims Analysis}

Medical and pharmacy administrative claims data from 3 regional commercial health plans were used to identify eligible patients. Data consisted of all medical billing for inpatient and outpatient or professional health services (UB04 and HCFA1500) and National Council for Prescription Drug Programs claim transmissions submitted by the health plans, representing more than 3.5 million commercial lives in the northeastern United States.
Patients included in the study were aged 18 years and older, continuously enrolled for 6 months before and throughout the study period (July 1, 2012-June 30, 2015), and had at least 2 diagnosis codes for breast cancer, lung cancer, melanoma, or CML occurring more than 30 days apart (Appendix A, available in online article). Analyses were performed individually for each tumor type using SAS version 9.4 (SAS Institute, Cary, NC).

The retrospective evaluation assessed overall utilization and costs, as well as cancer-specific costs for the various cancers. Oncology-related costs were determined by identifying the billing provider type and area of specialization through taxonomy codes.

\section{Phase 2: Development of an Episode-Based Payment Model}

Administrative claims data from the 3 regional commercial health plans were used to develop the model. Since not all aspects of the OCM methodology could be directly translated to a commercial plan, a crosswalk was developed to map OCM data elements to commercial claims data, proposing reasonable proxies when commercial data did not include variables available in Medicare data. This crosswalk, which was adapted from the OCM's methodology report, highlights each step of the development of an episode-based model that must be considered for a commercial adaptation of the OCM and includes rationale for suggested adaptations to commercial data. ${ }^{14}$ The full list of adaptations and the rationale for such adaptations can be found in Appendix B (available in online article). Development of the episode-based model involved the following steps:

Steps 1 and 2: Identification of Trigger Events and Episode Eligibility. In the OCM, a Part B (medical) claim for a chemotherapy drug and a cancer diagnosis or Part D (pharmacy) claim for a chemotherapy drug with a medical claim including a cancer diagnosis within the preceding 59 days triggers the start of an episode. For the study model, the Parts B and C requirements were substituted with any chemotherapy claim billed to the medical or pharmacy plans and adjudicated as paid. This episode identification process was an iterative one that is highly resource intensive when applied to a large dataset or long time period. Each potential trigger claim was checked against the remainder of the episode requirements. For an episode to be valid, it must have had a valid trigger event, and the patient must have remained eligible for medical and pharmacy benefits for the entire 6-month episode duration. All claims that occurred in the 6-month window were attributed to an episode, then the process was repeated for claims incurred more than 6 months from the previous valid trigger claim.

Steps 3 and 4: Assignment of Cancer Type and Episode Attribution. The CMS Innovation Center provides a diagnosis code list to use in assigning a cancer type to each episode in the OCM. An episode can have only 1 cancer type no matter 
Modeling Episode-Based Payments for Cancer Using Commercial Claims Data

TABLE 1 Results from Retrospective Claims Analysis in a Commercial Regional Health Plan

Baseline

Characteristics

Age, years, mean

(SD) [median]

All $(\mathrm{N}=80,748)$

Breast $(\mathrm{n}=51,859)$

Lung $(\mathrm{n}=15,969)$

Melanoma $(n=11,393)$

CML $(n=1,527)$

62.33 (12.98) [62]

$61.01 \quad(12.72) \quad[60]$

$67.43(11.04) \quad[68]$

$61.75(14.51)$

[62] $58.40 \quad(14.58)$

[59]

Age range, $\mathrm{n}(\%)$

\begin{tabular}{|c|c|c|c|c|c|c|c|c|c|c|}
\hline $18-20$ & 39 & $(0.05)$ & 8 & $(0.02)$ & 2 & $(0.01)$ & 25 & $(0.22)$ & 4 & $(0.26)$ \\
\hline $21-30$ & 585 & $(0.72)$ & 250 & $(0.48)$ & 23 & $(0.14)$ & 267 & $(2.34)$ & 45 & $(2.95)$ \\
\hline $31-40$ & 2,879 & $(3.57)$ & 2,004 & (3.86) & 139 & $(0.87)$ & 604 & $(5.30)$ & 132 & $(8.64)$ \\
\hline $41-50$ & 11,430 & $(14.16)$ & 8,858 & $(17.08)$ & 836 & $(5.24)$ & 1,474 & $(12.94)$ & 262 & $(17.16)$ \\
\hline $51-60$ & 21,381 & (26.48) & 14,886 & $(28.70)$ & 3,341 & $(20.92)$ & 2,773 & $(24.34)$ & 381 & $(24.95)$ \\
\hline $61-70$ & 22,250 & $(27.55)$ & 13,805 & $(26.62)$ & 5,058 & (31.67) & 3,004 & $(26.37)$ & 383 & (25.08) \\
\hline $71-80$ & 15,034 & (18.62) & 8,076 & $(15.57)$ & 4,643 & (29.08) & 2,103 & (18.46) & 212 & (13.88) \\
\hline $81+$ & 7,150 & $(8.85)$ & 3,972 & $(7.66)$ & 1,927 & $(12.07)$ & 1,143 & $(10.03)$ & 108 & $(7.07)$ \\
\hline \multicolumn{11}{|c|}{ Gender, n (\%) } \\
\hline Female & 65,783 & $(81.47)$ & 51,472 & $(99.25)$ & 8,491 & $(53.17)$ & 5,164 & $(45.33)$ & 656 & $(42.96)$ \\
\hline Male & 14,965 & $(18.53)$ & 387 & $(0.75)$ & 7,478 & $(46.83)$ & 6,229 & $(54.67)$ & 871 & $(57.04)$ \\
\hline \multicolumn{11}{|c|}{ Elixhauser Comorbidity Index score, ${ }^{a}$ n (\%) } \\
\hline 0 & 61,590 & $(76.27)$ & 40,388 & $(77.88)$ & 10,617 & $(66.49)$ & 9,304 & $(81.66)$ & 1,281 & $(83.89)$ \\
\hline 1 & 10,971 & (13.59) & 7,104 & $(13.70)$ & 2,404 & $(15.05)$ & 1,307 & $(11.47)$ & 156 & $(10.22)$ \\
\hline 2 & 5,221 & $(6.47)$ & 2,965 & $(5.72)$ & 1,693 & $(10.60)$ & 510 & $(4.48)$ & 53 & $(3.4 \%)$ \\
\hline $3+$ & 2,966 & $(3.67)$ & 1,402 & $(2.70)$ & 1,255 & $(7.86)$ & 272 & $(2.39)$ & 37 & $(2.42)$ \\
\hline
\end{tabular}

Three-year follow-up analyses

Annual medical utilization, ${ }^{\mathrm{b}}$ mean (SD) [median]

\begin{tabular}{|c|c|c|c|c|c|c|c|c|c|c|c|c|c|c|c|}
\hline Inpatient admissions & 0.01 & $(0.15)$ & {$[0]$} & 0.01 & $(0.12)$ & [0] & 0.03 & $(0.25)$ & {$[0]$} & 0.01 & $(0.11)$ & [0] & 0.01 & $(0.12)$ & {$[0]$} \\
\hline ALOS & 0.04 & $(0.89)$ & {$[0]$} & 0.03 & $(0.92)$ & [0] & 0.10 & $(1.03)$ & [0] & 0.02 & $(0.34)$ & [0] & 0.06 & $(0.77)$ & {$[0]$} \\
\hline ED visits & 0.48 & $(1.24)$ & [0] & 0.40 & (1.13) & [0] & 0.75 & (1.63) & {$[0]$} & 0.42 & (1.03) & [0] & 0.54 & $(1.50)$ & [0] \\
\hline Outpatient visits & 15.77 & $(17.85)$ & [10] & 14.82 & (16.73) & [9] & 16.96 & $(20.15)$ & [10] & 18.57 & $(18.46)$ & [14] & 17.13 & $(22.31)$ & [9] \\
\hline Laboratory tests & 7.26 & $(18.54)$ & [2] & 6.83 & $(16.22)$ & [2] & 8.65 & $(21.53)$ & [2] & 5.37 & $(14.47)$ & [2] & 20.61 & $(49.90)$ & [6] \\
\hline Surgica & 5.87 & $(8.20)$ & [3] & 5.29 & $(7.46)$ & [3] & 5.91 & $(8.93)$ & [3] & 8.45 & $(9.41)$ & [6] & 6.41 & $(10$. & [3] \\
\hline $\begin{array}{l}\text { Radiology (imaging } \\
\text { and/or treatment) }\end{array}$ & 9.41 & (14 & [4] & 9.69 & 5.3 & [4] & 11.82 & $(17.10)$ & [6] & 5.04 & $(9$. & [2] & 2.84 & $(5.72)$ & [1] \\
\hline \multicolumn{16}{|c|}{ Annual medical cost, ${ }^{\mathrm{c}, \mathrm{d}}$ mean (SD) [median] } \\
\hline Overall medical & 12,367 & $(33,577)$ & {$[3,630]$} & 14,549 & $(37,915)$ & {$[4,062]$} & 7,330 & $(20,387)$ & 199] & 10,148 & $(26,791)$ & {$[4,679]$} & 4,589 & $(8,928)$ & {$[1,645]$} \\
\hline Inpatient & 3,526 & $(5,376)$ & {$[1,926]$} & 4,323 & $(5,722)$ & {$[2,341]$} & 2,404 & $(2,916)$ & {$[1,538]$} & 5,112 & $(10,388)$ & {$[2,045]$} & 2,861 & $(3,031)$ & {$[1,589]$} \\
\hline ED & 665 & $(1,373)$ & [206] & 857 & $(1,545)$ & [314] & 252 & $(481)$ & [96] & 878 & $(1,838)$ & [252] & 408 & (723) & [172] \\
\hline Outpatient & 210 & $(803)$ & [84] & 256 & (923) & [113] & 124 & $(466)$ & [41] & 176 & $(716)$ & [94] & 82 & $(182)$ & [45] \\
\hline Laboratory & 006 & $(6,986)$ & [158] & 1,240 & $(2,834)$ & [193] & 464 & $(15,047)$ & [71] & 672 & $(1,489)$ & [198] & 989 & $(2,118)$ & [245] \\
\hline Surgical & 3,195 & $(8,517)$ & [640] & 3,891 & $(9,869)$ & [739] & 929 & $(2,452)$ & [278] & 3,238 & $(6,814)$ & {$[1,126]$} & 977.97 & $(3,458)$ & [194.23] \\
\hline Radiology & 4,425 & $(14,468)$ & [693] & 5,615 & $(17,103)$ & [813] & 2,299 & $(6,836)$ & [601] & 2,180 & $(7,058)$ & [514] & 618 & $(1,992)$ & [174] \\
\hline \multicolumn{16}{|c|}{ Annual pharmacy cost, ${ }^{\mathrm{c}}$ mean (SD) [median] } \\
\hline Overall Rx cost & 5,781 & $(20,079)$ & {$[1,011]$} & 4,944 & $(15,247)$ & {$[1,048]$} & 3,623 & $(9,344)$ & [890] & 4,488 & $(12,643)$ & [795] & 71,822 & $88,446)$ & {$[35,072]$} \\
\hline Oncology Rx cost & 5,827 & $(24,852)$ & {$[400]$} & 2,356 & $(9,484)$ & [357] & 7,984 & $(15,177)$ & {$[1,877]$} & 7,168 & $(16,829)$ & [611] & 96,426 & $(90,292)$ & {$[73,721]$} \\
\hline
\end{tabular}

Note: Values were calculated as per-patient averages over the study period.

aElixhauser Comorbidity Index scores were calculated from claims incurred during the baseline period and based on HCUP software. 20

${ }^{b}$ Patients with no utilization in a particular category were counted as zero.

'All cost information was risk adjusted.

${ }^{d}$ Oncology-related costs are determined by taxonomy of the billing provider. For mean (SD) [median], oncology-related medical costs =1,948 (8,367) [279];

nononcology-related costs $=10,418(19,787)[3,350]$.

$A L O S=$ average length of stay; $C M L=$ chronic myelogenous leukemia; ED = emergency department; HCUP= Healthcare Cost and Utilization Project; Rx=prescription;

$S D=$ standard deviation.

the clinical condition of the patient. For commercial adaptation, International Classification of Diseases, Ninth/Tenth Revision, Clinical Modification (ICD-9/10-CM) codes were used to identify the cancer type (Appendix A). Each episode was assigned to only 1 provider according to OCM methodology, which defines the attributable physician as the one with the most evaluation and management (E\&M) codes during the episode. Presumably this is the provider who is the primary oncology 
Step 1

Identify Trigger Events

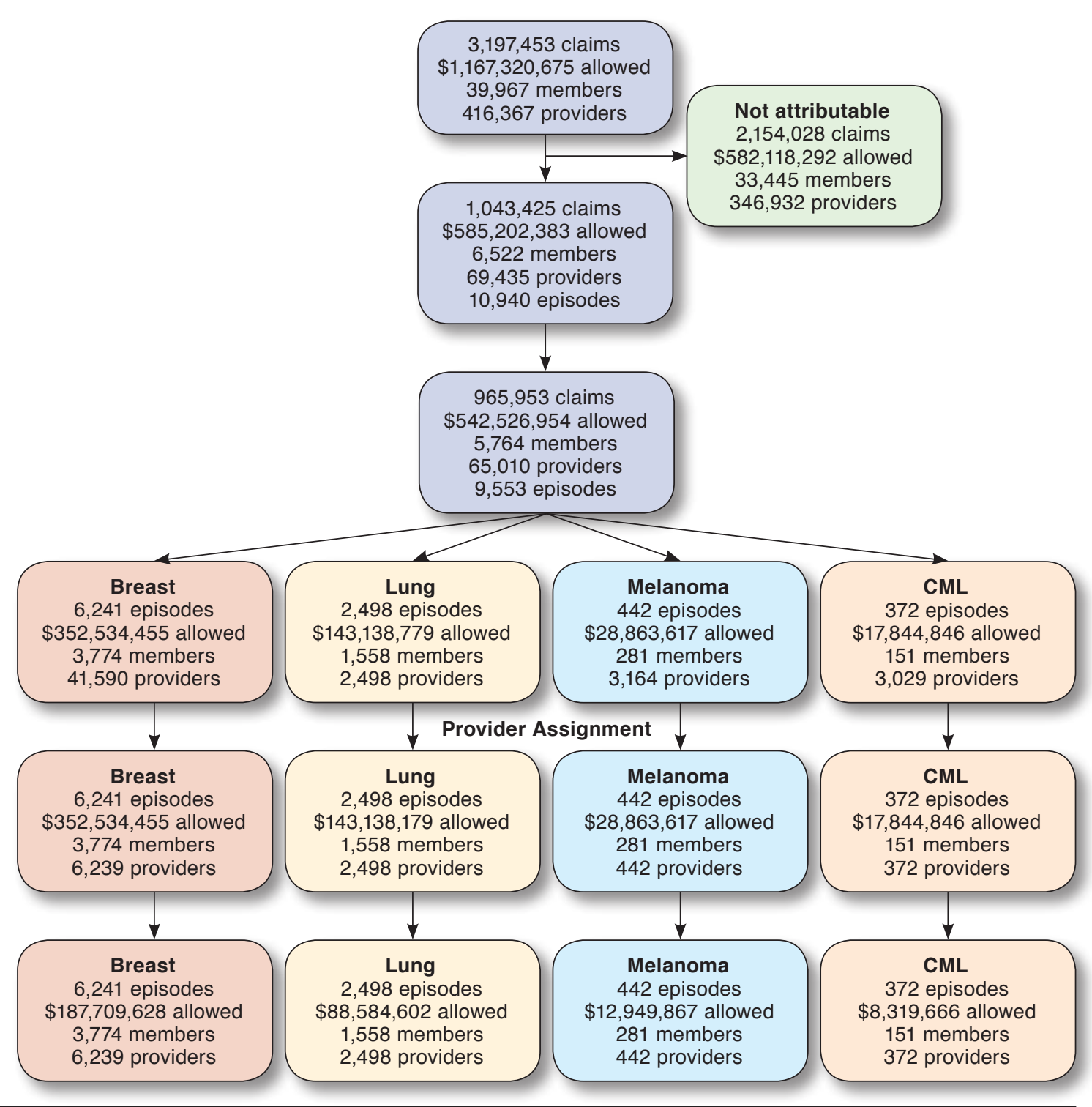

Step 2

Episode Eligibility

Continuous eligibility for the episode period applied for fairness of calculation.

\section{Step 3}

Assign Cancer Type In realilty not all claims will map to a valid cancer code.

Step 4

Episode Attribution

Step 5

Baseline Expenditures
$1,167,320,675$ allowed

39,967 members

416,367 providers

$1,043,425$ claims

69,435 providers

10,940 episodes

965,953 claims

9,553 episodes
(3)

33,445 members

346,932 providers

, 844,846 allowed

151 members

372 episodes

(244,846 allowed

51 members
CML

19,66 allowed

151 members

372 providers

$C M L=$ chronic myelogenous leukemia .

physician treating the patient's cancer and coordinating care during the episode.

Step 5: Calculation of Episode Expenditures. After identification and attribution of episodes, the OCM model sums the Medicare fee-for-service payments incurred during each episode. In the commercial adaptation, all medical and pharmacy reimbursements were included as episode expenditures. In order to remove the bias introduced by deductibles, copays, and coinsurance, the commercially adopted model used the allowed amount from the claims data to represent the expen- ditures for each visit/utilization. The allowed amount is the amount that the insurer pays for each covered procedure and is usually the amount they have deemed the services received to be worth. These amounts were used to generate the baseline price that was risk-adjusted using age, gender, and comorbidity index score to achieve the target amount. In the OCM, baseline prices are calculated using a prediction model, calibrated using the national set of baseline episodes and baseline episode expenditures. ${ }^{14}$ The CMS Innovation Center estimates the prediction model by regressing baseline episode expenditures on a list of covariates determined to influence episode 


\begin{tabular}{|c|c|c|c|c|}
\hline \multicolumn{5}{|c|}{$\begin{array}{cl}\text { TABLE } 2 & \begin{array}{l}\text { Results from Retrospective Claims } \\
\text { Analysis in a Commercial Regional } \\
\text { Health Plan }\end{array}\end{array}$} \\
\hline Cancer Type & $\begin{array}{c}\text { Patients in } \\
\text { Study }\end{array}$ & $\begin{array}{c}\text { Proportion of } \\
\text { Patients with } \\
\geq 1 \text { Qualifying } \\
\text { Episode in a } \\
\text { Given Year }\end{array}$ & $\begin{array}{l}\text { Proportion of } \\
\text { Total Annual } \\
\text { Cost Included } \\
\text { in Episodes }^{b} \\
\end{array}$ & $\begin{array}{c}\text { Average } \\
\text { Number of } \\
\text { Episodes Per } \\
\text { Patient Per } \\
\text { Yearb } \\
\end{array}$ \\
\hline Breast & 27,577 & $12 \%$ & $49 \%$ & 1.53 \\
\hline Lung & 5,935 & $24 \%$ & $60 \%$ & 1.46 \\
\hline Melanoma & 5,776 & $4 \%$ & $34 \%$ & 1.42 \\
\hline CML & 679 & $21 \%$ & $52 \%$ & 1.94 \\
\hline \multicolumn{5}{|c|}{ 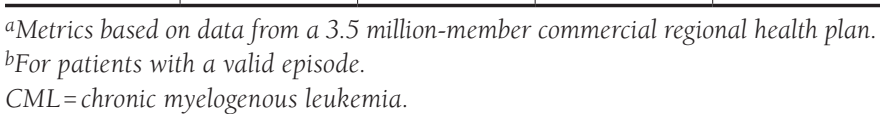 } \\
\hline
\end{tabular}

expenditures; some of these covariates are as follows: cancer type, age, sex, dual eligibility, episode length, type of chemotherapy drugs used during episodes, participation in clinical trials, and receipt of radiation therapy ${ }^{15}$ Target price is calculated after adjustments for trends and novel therapies by applying the OCM discount, which is $4 \%$ for one-sided risk-sharing arrangements and 2.75\% for two-sided risk arrangements. ${ }^{15}$

The model variables were changed from the OCM to the commercially adapted version, since Medicare uses national metrics not available to a commercial health plan. If implemented in a commercial plan, the modeling would need to be structured in an actuarially sound manner, preferably with a commercially available risk grouper. The modeling step must be validated for actuarial soundness before use in an episodebased payment program, since the variables and coefficients will vary from plan to plan. In the commercial adaptation, the risk adjustments and modeling were based on 5 years of data, which led to more reasonable risk adjustments than models based on a shorter time span.

\section{Results}

\section{Phase 1: Retrospective Claims Analysis}

A total of 80,748 patients were identified and included in the study. Table 1 displays patient baseline characteristics, medical utilization, and costs measured, segmented by cancer type. Overall, $81 \%$ of patients were female, and the average age across all cohorts was 62 years. The majority of patients were diagnosed with breast cancer (64\%), while 20\%, 14\%, and 2\% were diagnosed with lung cancer, melanoma, and CML, respectively. Average total (median) annual medical cost for all patients was $\$ 12,367$ (\$3,630), of which oncology-related costs, determined by taxonomy of the billing provider, represented about $16 \%$.

\section{Phase 2: Development of an Episode-Based Payment Model}

A total of 39,967 patients qualified for episode analysis. The adapted OCM model was applied to data from 5,764 patients,

\begin{tabular}{l|c|c|c|c}
\multicolumn{4}{c}{ TABLE 3 Predicted and Benchmark Prices } \\
\hline $\begin{array}{l}\text { Tumor } \\
\text { ype }\end{array}$ & $\begin{array}{c}\text { Actual Episode } \\
\text { Expenditure, \$ }\end{array}$ & $\begin{array}{c}\text { Baseline } \\
\text { Expenditure, \$ }\end{array}$ & $\begin{array}{c}\text { Predicted } \\
\text { Expenditure, \$ }\end{array}$ & $\begin{array}{c}\text { Target } \\
\text { Amount, \$ }\end{array}$ \\
\hline Breast & $352,534,455$ & $187,709,628$ & $186,965,983$ & $187,497,747$ \\
\hline ung & $143,138,779$ & $88,584,602$ & $90,895,915$ & $90,097,363$ \\
\hline elanoma & $28,863,617$ & $12,949,867$ & $12,093,762$ & $12,521,814$ \\
\hline ML & $17,844,846$ & $8,319,666$ & $8,954,749$ & $8,637,207$ \\
\hline ML=chronic myelogenous leukemia.
\end{tabular}

representing 9,553 episodes meeting the analysis criteria. Figure 1 depicts the adjudication process. The number of patients with each cancer type, percentage of patients with at least 1 qualifying episode, percentage of total annual cost included in the episodes, and average number of episodes per patient per year are presented in Table 2. The final sample consisted of 6,241 episodes, 2,498 episodes, 442 episodes, and 372 episodes, for breast cancer, lung cancer, melanoma, and CML, respectively.

Overall, actual 6-month episode expenditures for these patients across all 4 cancer types were $\$ 542 \mathrm{M}$, while the episode-eligible calculated target amount for the same population was $\$ 299 \mathrm{M}$ (Table 3). The percentage of total annual costs included in episodes was 49\%,60\%,34\%, and 52\% for breast cancer, lung cancer, melanoma, and CML, respectively (Table 2). In all 4 cancers types, the actual episode expenditure was higher than the target amount.

\section{Discussion}

In this study, an episode-based payment model was developed for commercial health plans based on the CMS Innovation Center's OCM. In doing so, several learnings that highlight the challenges of adapting the OCM methodology to commercially insured patients were identified.

\section{Identification of Trigger Events and Episode Eligibility}

The retrospective claims analysis revealed that the exclusion and adjustment rules outlined in the OCM methodology had a large effect on results. Given that episodes are triggered by claims for chemotherapy, patients who are in remission, undergoing surgery or radiation therapies, or are erratic with therapy often do not meet criteria to trigger an episode. Although a patient can have a maximum of 2 episodes in a year, the majority of patients in our study had no qualifying episodes (less than $25 \%$ of cancer patients qualified for episode-based payments under the OCM definition, representing $49 \%$ of total costs).

\section{Assignment of Cancer Type and Episode Attribution}

This model focused on 4 cancer types. In a broader adaptation of the model, a plan must expand the diagnosis code list to include all neoplasia of interest. At the time of this writing, it was necessary to use both ICD-9/10-CM codes in order to 
have sufficient data to accurately calculate model adjustments. Application of this model to real-world data also revealed that it is possible for episodes to be attributed to providers whose specialty is not related to oncology, if that provider submits claims for the most E\&M codes. Health plans will need to determine how to handle such cases and whether they should be disqualified. An alternative approach could be to attribute the episode to the provider meeting predefined oncology specialty codes, as is done in the OCM, where the attributable physician must be an oncology-related practitioner.

\section{Calculation of Baseline Episode Expenditures}

For Medicare plans, reimbursement rates are set by the CMS Innovation Center and are not subject to negotiation. Commercial plans may negotiate rates with individual providers, and the negotiated rates are kept confidential. To minimize some of the differences in baseline episode expenditure calculations between the OCM and our model, standardized pricing can be developed at the procedure code level by using the median price per unit for each procedure code. An argument can be made that this adjustment is not necessary, since the economic effect of negotiated reimbursement rates is largely ignored in the calculated episode expenditures. Not adjusting the rates may lead to more incentive payments for providers with lower reimbursement rates and more risk sharing with providers, who have higher negotiated reimbursement rates, thus narrowing the gap between the 2 models.

\section{Accounting for Model Overlap in the Baseline}

In a commercial implementation, the actuarial effect of concomitant alternative payment models will have to be carefully considered for the plan and providers before a decision can be reached on how to deal with overlapping initiatives, such as episode-based programs and other risk-sharing arrangements. In the OCM, providers are excluded if they are participating in certain other demonstration projects or alternative payment models. For plans that are new to episode-based payment models, other operational considerations should be recognized, such as frequency of episode review (e.g., code lists) and communication of episode details and financials to providers. Additional details on general operational considerations of an episode-based payment initiative are readily available in the literature. ${ }^{8,16,17}$

\section{Predictive Model Development and Data Requirements}

Estimating the economic effect of an OCM-like episode-based payment model in a commercial population requires considerable analysis and planning. The development of a predictive model is an important step in the calculation of the episode prices and adapting the generalized linear model of the OCM for implementation in a commercial health plan may be the most intricate and involved part of the process. Care must be taken to ensure that this model generates results that are actuarially sound for the plan and participating providers.

Generation and use of this model is an iterative process that must be periodically revisited to ensure that the included covariates remain significant in the model and new covariates that may affect the model are evaluated for inclusion. A plan to review and update the model should be established concomitantly with model development. Also, transparency regarding the development, implementation, and maintenance of the predictive model may help alleviate provider concerns regarding how baseline costs and target amounts are calculated. In this simple model, we only included age, gender, and comorbidity index scores. In a real-world setting, the health plan would need to consult actuarial experts for accurate variable selection and calculations. The CMS Innovation Center publishes details of its prediction model and code lists in the OCM provider portal. ${ }^{15,18}$

\section{Adjustment for Novel Therapies}

Including accommodations to incorporate novel therapies is important, since the rate of innovation in oncology is resulting in frequent new product launches, often at significantly higher prices than the current standard of care. Predicted episode expenditures based on historic data will always lag episode costs that include expensive, novel therapies. A different approach may be to discount the baseline price by the median proportion of utilization of the novel agent across the provider population. Careful consideration should be given to reimbursement mechanisms for novel therapies such that use of an agent that has a clinical advantage over previous therapies is not discouraged. The CMS Innovation Center's methodology document discusses how this adjustment may be altered in the future for the OCM. ${ }^{15}$

\section{Performance-Based Payments}

In the OCM, actual expenditures are reconciled against a target price for episodes of care. Depending on the risk-sharing arrangement, this model provides insights into the possible implications for performance-based payments to providers. The model in this study directly affects the target amount and thus performance-based payment or recoupment. Typically, in episode-based payment models, discounts are applied to the benchmark amounts depending on whether the provider chooses a one-sided or two-sided risk arrangement. In the one-sided risk arrangement, the provider is eligible for gain sharing if the episodes are less than the target amount but is not responsible to pay a risk share amount if the episode prices exceed the target amounts. In the two-sided risk agreement, the provider is eligible for gain share payments from the plan and risk share payments to the plan if episode costs exceed the target amounts. The discount amounts specified in the OCM differ for these 2 risk arrangements, with the deeper discount applied to the one-sided risk arrangement. It may be optimal 
for a plan, depending on analysis of internal data, to alter the discount percentages from those used in the OCM.

The CMS Innovation Center also specifies how performance bonuses are calculated by using the performance multiplier, which is based on results from claims data analyses and a practice's performance on quality and practice transformation activities. This multiplier has the potential to reduce or eliminate the performance bonus paid to providers. Therefore, payers must review the elements of the performance multiplier, and their respective weights, and modify as necessary to ensure appropriate and fair assessment. In addition, the CMS Innovation Center pays principle accounting providers a flat fee of $\$ 160$ per patient per month to offset costs of coordinating care for patients during the episode. For commercial plans implementing episode payments, paying a similar fee is anticipated for the program to be successful. Consideration should be given, however, to varying the fee based on the complexity of the episode and overall coordination needs of patients while they are in an episode.

\section{Effect of Episode-Based Payments on Providers}

Reviewing and implementing criteria for this model provided information valuable for providers. Since payment is attributed to only 1 provider for each episode, the provider who receives this payment is identified by the episode adjudication rules. These rules rely on counting E\&M Current Procedural Terminology codes, as detailed in the OCM methodology. In evaluating episodes, it is clear that not all oncologists are consistent in billing E\&M codes. Providers should be encouraged to review the technical details of episode calculations to ensure that proper codes are being billed, leading to accurate identification of the attributable physician.

\section{Effect of Episode-Based Payments on the Health Care Continuum}

Although episode-based payment methodologies have direct and visible consequences for payers and providers, the effect can reach other areas of the health care continuum. The increasing need for pharmacoeconomic data and information will become apparent as providers are incentivized to make value-based choices involving diagnostic and treatment decisions. According to 2018 guidelines for drug and device manufacturers put forth by the U.S. Department of Health and Human Services, individual providers are considered "a payor, formulary committee, or other similar entity with knowledge and expertise in the area of health care economic analysis carrying out its responsibilities for the selection of drugs for coverage or reimbursement." ${ }^{19}$ Thus, moving forward, individual providers participating in these episode-based payment models and making value-based treatment decisions will require additional training on pharmacoeconomics.

A therapy with a higher acquisition cost, but near-term economic benefit in avoiding costly adverse outcomes, can result in financial savings for the provider and possibly a better clinical experience for the patient. Pharmaceutical and device manufacturers will experience new contracting challenges, since rebates and incentives negotiated with health plans may not affect providers' episode calculations. This may place emphasis on the "list price," such as the average sales price, of a product, which directly affects episode costs. Providers will have greater incentive to choose products based on their effect on total cost of care, and the duty will rest on manufacturers to help inform this decision.

\section{Limitations}

This project has some limitations to consider. The study model was developed based on data from 3 regional health plans representing more than 3.5 million commercial lives in the northeastern United States. Trends and patterns regarding utilization and cost may differ in other plans, geographies, or lines of business. We tried to reduce the bias introduced by payments incurred by patients, such deductibles, copays, and coinsurance, in the commercially adopted model by using the allowed amount from the claims data. However, if patients steered away from care due to higher than affordable payments, their services were not captured and therefore not included in the analysis. Plans with high deductibles, for example, will need to be cognizant of patients not receiving services due to such constraints.

Results presented are an estimate of possible outcomes for a health plan using an episodic-payment method. OCM adjustments require use of a generalized linear model. Variables used in the linear model included gender, age, and Elixhauser Comorbidity Index scores as integer values. In implementation, additional variables may be required to make results of the model applicable to specific health plans, and other changes may be necessary to ensure that an episode-based payment arrangement is actuarially sound.

\section{Conclusions}

This project assessed the feasibility of implementing an episode-based payment system in a commercial health plan. From the exploration, OCM-like methodology can be implemented in commercial plans, while accounting for the potential challenges and effect. The development process led to numerous learnings that may be of interest to commercial payers seeking to implement an innovative payment model based on the OCM. Of note, given that episodes are triggered by claims for chemotherapy, future evaluations of other trigger events may be warranted to assess effect on results. As commercial payers look for ways to control growth in oncology spending, episodebased payment models similar to the OCM may represent a viable option, albeit with adjustments required to the OCM methodology to be applicable to populations beyond Medicare. 


\section{Authors}

MICHAEL POLSON, PharmD, MS; TODD LORD, PharmD, AE-C, CDOE; THEMMI EVANGELATOS, PharmD, MSBA; ANNE KANGETHE, PharmD, MPH, PhD; LINDSAY C. SPEICHER, JD; and SERVI BARRIENTOS, BS, Magellan Rx Management, Middletown, Rhode Island. CHRISTOPHER ZACKER, RPh, PhD, Novartis, East Hanover, New Jersey.

AUTHOR CORRESPONDENCE: Lindsay C. Speicher, JD, Magellan Rx Management, 88 Silva Ln., Tech 4, Ste. 110, Middletown, RI 02842. Tel.: 401.344.1105; E-mail: lspeicher@magellanhealth.com.

\section{DISCLOSURES}

This study was conducted by Magellan Rx Management with funding contributed by Novartis. Zacker is an employee of Novartis. The other authors are employed by Magellan Rx Management and have nothing to disclose.

\section{REFERENCES}

1. American Cancer Society. Cancer facts \& figures 2016. Available at: https://www.cancer.org/research/cancer-facts-statistics/all-cancer-factsfigures/cancer-facts-figures-2016.html. Accessed November 11, 2018.

2. IMS Institute for Healthcare Informatics. Global oncology trend report: a review of 2015 and outlook to 2020. June 2016. Available at: https:// morningconsult.com/wp-content/uploads/2016/06/IMS-Institute-GlobalOncology-Report-05.31.16.pdf. Accessed January 4, 2019.

3. Dreyfus J. Oncology care management-the next horizon for value-based purchasing. July 1, 2016. Available at: https://www.theoncologygroup.com/ pdf/Oncology-Care-Management.pdf. Accessed November 11, 2018.

4. Kolodziej M. The Oncology Care Model: roadmap or distraction for commercial payers? September 6, 2016. Available at: https://www.onclive.com/ publications/oncology-business-news/2016/september-2016/the-oncologycare-model-roadmap-or-distraction-for-commercial-payers. Accessed November 11, 2018.

5. Carey BP. Oncology Care Model. Foley Hoag. July 1, 2016. Available at: https://www.foleyhoag.com/publications/alerts-and-updates/2016/june/ oncology-care-model. Accessed November 11, 2018.

6. Pound WT. Health cost containment and efficiencies. Episode-of-care payments. NCSL Briefs for State Legislators, no. 3, May 2010. Available at: http://www.ncsl.org/portals/1/documents/health/EPISODE_of_CARE-2010. pdf. Accessed November 11, 2018.

7. Newcomer LN, Gould B, Page RD, Donelan SA, Perkins M. Changing physician incentives for affordable, quality cancer care: results of an episode payment model. J Oncol Pract. 2014;10(5):322-26.
8. Mechanic RE. Opportunities and challenges for episode-based payment. N Engl J Med. 2011;365(9):777-79.

9. Shih T, Chen LM, Nallamothu BK. Will bundled payments change health care? Examining the evidence thus far in cardiovascular care. Circulation. 2015;131(24):2151-58.

10. Narayanan S, Hautamaki E. Oncologist support for consolidated payments for cancer care management in the United States. Am Health Drug Benefits. 2016;9(5):280-88.

11. Gruessner V. How to prevent healthcare underuse in bundled payment models. HealthPayerIntelligence. January 6, 2017. Available at: https:// healthpayerintelligence.com/news/how-to-prevent-healthcare-underuse-inbundled-payment-models. Accessed November 11, 2018.

12. Center for Healthcare Quality and Payment Reform. Transitioning to episode-based payment. Available at: http://www.chqpr.org/downloads/transitioningtoepisodes.pdf. Accessed November 11, 2018.

13. Abt Associates. First annual report from the evaluation of the Oncology Care Model: baseline period. Contract \#HHSM-500-2014-000261 T0003. February 1, 2018. Available at: https://downloads.cms.gov/files/cmmi/ocmbaselinereport.pdf. Accessed November 11, 2018.

14. Rocque GB, Williams CP, Kenzik KM, et al. Where are the opportunities for reducing health care spending within alternative payment models? J Oncol Pract. 2018;14(6):e375-e383.

15. Strawbridge L, Mortimer L, Muldoon D, York A. OCM performancebased payment methodology [webinar]. Center for Medicare \& Medicaid Innovation. April 20, 2016. Available at: https://innovation.cms.gov/Files/ slides/ocm-performancemethod-slides.pdf. Accessed January 4, 2019.

16. Hussey PS, Sorbero ME, Mehrotra A, Liu H, Damberg CL. Episode-based performance measurement and payment: making it a reality. Health Aff (Millwood). 2009;28(5):1406-17.

17. de Brantes F, Rosenthal MB, Painter M. Building a bridge from fragmentation to accountability—the Prometheus Payment Model. N Engl J Med. 2009;361(11):1033-36.

18. The Center for Medicare \& Medicaid Innovation. Oncology Care Model. Available at: https://innovation.cms.gov/initiatives/Oncology-Care/. Accessed November 11, 2018.

19. U.S. Food and Drug Administration, Center for Drug Evaluation and Research. Drug and device manufacturer communications with payors, formulary committees, and similar entities-questions and answers. Guidance for industry and review staff. June 2018. Available at: https://www.fda.gov/ downloads/drugs/guidancecomplianceregulatoryinformation/guidances/ ucm537347.pdf. Accessed November 11, 2018.

20. Agency for Healthcare Research and Quality, Healthcare Cost and Utilization Project (HCUP). Elixhauser Comorbidity Software. Available at: https://www.hcup-us.ahrq.gov/toolssoftware/comorbidity/comorbidity.jsp. Accessed November 11, 2018. 


\section{APPENDIX A Diagnosis Definitions}

\begin{tabular}{|c|c|c|}
\hline Condition & ICD-9-CM Codes & ICD-10-CM Codes \\
\hline Breast cancer & $\begin{array}{l}\text { Female: } 174.0,174.1,174.2,174.3,174.4,174.5,174.6,174.8,174.9 \\
\text { Male: } 175.0,175.9\end{array}$ & $\begin{array}{l}\text { Female: C50.019 C50.119 C50.219 C50.319 C50.419 C50.519 } \\
\text { C50.619 C50.819 C50.919 } \\
\text { Male: C50.029, C50.929 }\end{array}$ \\
\hline Lung cancer & $\begin{array}{l}\text { 62.0, } 162.2,162.3,162.4,162.5,162.8,162.9 \\
\text { Pleura: } 163.0,163.1,163.8,163.9\end{array}$ & $\begin{array}{l}\text { C33, C34.00, C34.10, C34.2, C34.30, C34.80, C34.90 } \\
\text { Pleura: C38.4 }\end{array}$ \\
\hline Melanoma & $172.1,172.2,172.3,172.4,172.5,172.6,172.7,172.8,172.9$ & $\begin{array}{l}\text { C43.0, D03.0, C43.10, D03.10, D03.11, D03.12, C43.20, D03.20, } \\
\text { D03.21, D03.22, C43.30, C43.31, C43.39, D03.30, D03.39, C43.4, } \\
\text { D03.4, C43.59, D03.51, D03.52, D03.59, C43.60, D03.60, D03.61, } \\
\text { D03.62, C43.70, D03.70, D03.71, D03.72, C43.8, D03.8, C43.9, } \\
\text { D03.9 }\end{array}$ \\
\hline$\overline{\mathrm{CML}}$ & $205.10,205.11,205.12$ & C92.10, C92.11, C92.12 \\
\hline
\end{tabular}

\section{APPENDIX B CMS OCM Crosswalk for Adaptation to Commercial Data}

\begin{tabular}{|c|c|c|c|}
\hline Section & CMS Documentation & Commercial Adaptation & Rationale for Transition \\
\hline 1.1 .1 & $\begin{array}{l}\text { Episodes are triggered via Part B or Part D } \\
\text { claims for chemotherapy }\end{array}$ & $\begin{array}{l}\text { Use all medical (CMS-1500/UB-04) claims in } \\
\text { place of Part B and all ambulatory pharmacy } \\
\text { (NCPDP) claims in place of Part D. }\end{array}$ & $\begin{array}{l}\text { Commercial insurance does not have Part B or } \\
\text { Part D claim types designed in the same way as } \\
\text { Medicare. Medical (e.g., CMS-1500, UB-04) and } \\
\text { pharmacy claims (NCPDP) are an appropriate } \\
\text { alternative. }\end{array}$ \\
\hline 1.1 .1 & Qualifying codes are listed in the OCM portal & $\begin{array}{l}\text { Use J9000-J9999 (drug codes) or } 96400, \\
96408,96425,96520 \text {, and } 96530 \text { (chemo- } \\
\text { therapy admin codes) for medical chemother- } \\
\text { apy claims and FDB Standard Therapeutic } \\
\text { Class } 30 \text { for a list of NDC numbers until the } \\
\text { CMS code sets are available. }\end{array}$ & $\begin{array}{l}\text { Only OCM providers can access the portal that } \\
\text { contains the specific procedure and drug codes } \\
\text { required for identification of trigger events, and } \\
\text { receipt of the exact code list will not take place } \\
\text { until official enrollment in the OCM program. } \\
\text { Procedure codes used for medical chemotherapy } \\
\text { claims and FDB Standard Therapeutic Class } 30 \\
\text { were used for a list of NDC numbers. }\end{array}$ \\
\hline 1.1 .2 & $\begin{array}{l}\text { Beneficiary is enrolled in Medicare Parts A } \\
\text { and B }\end{array}$ & $\begin{array}{l}\text { Member is eligible for both medical and } \\
\text { pharmacy benefit. }\end{array}$ & $\begin{array}{l}\text { Eligibility criteria must be modified for commer- } \\
\text { cial adoption. }\end{array}$ \\
\hline 1.1 .2 & $\begin{array}{l}\text { Beneficiary does not receive the Medicare } \\
\text { ESRD benefit }\end{array}$ & N/A & $\begin{array}{l}\text { Eligibility criteria must be modified for commer- } \\
\text { cial adoption. }\end{array}$ \\
\hline 1.1 .2 & $\begin{array}{l}\text { Beneficiary has Medicare as his or her pri- } \\
\text { mary payer }\end{array}$ & $\begin{array}{l}\text { Exclude patients for whom the plan is a } \\
\text { secondary payer. }\end{array}$ & $\begin{array}{l}\text { Eligibility criteria must be modified for commer- } \\
\text { cial adoption. }\end{array}$ \\
\hline 1.1 .2 & $\begin{array}{l}\text { Beneficiary is not covered under Medicare } \\
\text { Advantage or any other group health program }\end{array}$ & N/A & $\begin{array}{l}\text { Eligibility criteria must be modified for commer- } \\
\text { cial adoption. }\end{array}$ \\
\hline 1.1 .2 & [No mention of continuous eligibility] & $\begin{array}{l}\text { Exclude episodes in which the member loses } \\
\text { eligibility before the end of the } 6 \text {-month } \\
\text { episode. }\end{array}$ & $\begin{array}{l}\text { Eligibility criteria must be modified for com- } \\
\text { mercial adoption. As in OCM, if the patient dies } \\
\text { or elects to receive hospice care before the end } \\
\text { of } 6 \text { months, he or she is still considered epi- } \\
\text { sode eligible. Also, in accordance with the OCM } \\
\text { methodology, this implementation allowed for an } \\
\text { episode to be shorter than } 6 \text { months in duration } \\
\text { only if the patient died during the episode. }\end{array}$ \\
\hline 1.1 .3 & Assignment of cancer type & $\begin{array}{l}\text { This adaptation of the OCM model was } \\
\text { concerned with } 4 \text { cancer types: breast, lung, } \\
\text { melanoma, and CML. Therefore, } 1 \text { of these } \\
4 \text { cancer types was assigned based on the } \\
\text { number of diagnosis codes accumulated over } \\
\text { claims with E\&M codes. }\end{array}$ & $\begin{array}{l}\text { The cancer type is assigned using claim diagno- } \\
\text { sis codes occurring on claims with E\&M proce- } \\
\text { dure codes. The E\&M code range considered for } \\
\text { this purpose is } 99201-99205 \text { or } 99211-99215 \text {. As } \\
\text { with the other code listings, the exact diagnosis } \\
\text { coding specified by CMS is only available to } \\
\text { entities participating in OCM via the provider } \\
\text { portal. }\end{array}$ \\
\hline
\end{tabular}




\section{APPENDIX B CMS OCM Crosswalk for Adaptation to Commercial Data (continued)}

\begin{tabular}{|c|c|c|c|}
\hline Section & CMS Documentation & Commercial Adaptation & Rationale for Transition \\
\hline 1.2 & $\begin{array}{l}\text { Use the Part B carrier file to identify E\&M } \\
\text { visits }\end{array}$ & $\begin{array}{l}\text { Use medical claims (CMS-1500/UB-04) with } \\
\text { the exception of inpatient claims. Episodes } \\
\text { that can be attributed to providers whose spe- } \\
\text { cialty does not necessarily lend itself to being } \\
\text { included in oncology episodes (e.g., a patient } \\
\text { sees a psychiatrist several times during an } \\
\text { episode period resulting in that provider hav- } \\
\text { ing the highest number of E\&M claims and } \\
\text { having reported the cancer diagnosis, since it } \\
\text { is a major contributor to the patient's mental } \\
\text { health) should be disqualified. The remain- } \\
\text { der of this section of the OCM methodology } \\
\text { should be implementable in a commercial } \\
\text { setting. }\end{array}$ & $\begin{array}{l}\text { Although the terminology is not used in the } \\
\text { OCM documentation, this implementation } \\
\text { referred to the provider for which an episode } \\
\text { is attributed to as the principally accountable } \\
\text { provider. Episodes are attributed by tax ID to } \\
\text { the practice associated with the most E\&M visits } \\
\text { with a cancer diagnosis during the } 6 \text {-month epi- } \\
\text { sode with details included on how to break ties. }\end{array}$ \\
\hline 1.2 & [Data errors not addressed] & $\begin{array}{l}\text { If no attributable provider can be found then } \\
\text { delete the episode }\end{array}$ & $\begin{array}{l}\text { OCM states a methodology to attribute a par- } \\
\text { ticular provider to an episode. There were a few } \\
\text { cases in which executing those rules did not } \\
\text { identify a provider but identified a provider ID } \\
\text { for a large practice. Further rules could be devel- } \\
\text { oped to account for these rare circumstances. }\end{array}$ \\
\hline 2.1 & $\begin{array}{l}\text { Parts A and B expenditures come from } \\
\text { the Inpatient, SNF, Outpatient, Carrier, } \\
\text { DMEPOS, HHA, and Hospice claims files. } \\
\text { Medicare expenditures will be adjusted } \\
\text { to exclude indirect medical education and } \\
\text { disproportionate share hospital payments, } \\
\text { as well as inpatient pass through amounts, } \\
\text { which include direct graduate medical educa- } \\
\text { tion, capital-related costs, and bad debt. }\end{array}$ & $\begin{array}{l}\text { Use medical (CMS-1500/UB-04) claims. } \\
\text { Significant adaptations were necessary to } \\
\text { implement this methodology in a commercial } \\
\text { population. }\end{array}$ & $\begin{array}{l}\text { Most of these types of expenditures are not } \\
\text { directly related to services provided; therefore, } \\
\text { this does not pose a problem when using com- } \\
\text { mercial administrative medical and pharmacy } \\
\text { claims data. }\end{array}$ \\
\hline 2.1 & $\begin{array}{l}\text { Part D expenditures come from the Part } \\
\text { D claims files and include only the LICS } \\
\text { amount and } 80 \% \text { of the GDCA threshold. }\end{array}$ & Use pharmacy (NCPDP) claims & $\begin{array}{l}\text { These populations and calculations are not appli- } \\
\text { cable to a commercial population. }\end{array}$ \\
\hline 2.1 & $\begin{array}{l}\text { Parts A and B expenditures will be sourced } \\
\text { from CMS standardized payment files }\end{array}$ & $\begin{array}{l}\text { Standardize payments to remove geographic } \\
\text { variation. One way is to calculate the median } \\
\text { cost per unit for all CPT/revenue codes and } \\
\text { use this as the standardized calculation. }\end{array}$ & $\begin{array}{l}\text { In this implementation, regional health plans } \\
\text { were used to minimize these differences. There } \\
\text { are also differences in contracted rates in com- } \\
\text { mercial data that may lead to similar bias in } \\
\text { the results. In order to minimize some of these } \\
\text { differences, standardized pricing was developed } \\
\text { at the procedure code level by using the median } \\
\text { price per unit for each procedure code. }\end{array}$ \\
\hline 2.1 & & $\begin{array}{l}\text { A safeguard needs to be in place to account } \\
\text { for misbilling of J-code units as well as mis- } \\
\text { cellaneous J-code billing. }\end{array}$ & $\begin{array}{l}\text { J-code units are inconsistently reported, which } \\
\text { can substantially affect calculated baseline } \\
\text { prices. }\end{array}$ \\
\hline 2.2 & $\begin{array}{l}\text { In the event that an OCM beneficiary was } \\
\text { aligned with other CMS models during the } \\
\text { baseline period, baseline expenditures will be } \\
\text { adjusted accordingly. }\end{array}$ & $\begin{array}{l}\text { Consider excluding episodes that conflict } \\
\text { with other payment initiatives. }\end{array}$ & $\begin{array}{l}\text { Patients who had overlapping alternative pay- } \\
\text { ment models from the data were removed to } \\
\text { account for oncology episode-based payments } \\
\text { that overlap with other active payment models, } \\
\text { such as accountable care organizations. }\end{array}$ \\
\hline 2.3 & Sequestration adjustment & N/A & $\begin{array}{l}\text { This adjustment does not apply to the commer- } \\
\text { cial population. }\end{array}$ \\
\hline
\end{tabular}




\section{APPENDIX B CMS OCM Crosswalk for Adaptation to Commercial Data (continued)}

\begin{tabular}{|c|c|c|c|}
\hline Section & CMS Documentation & Commercial Adaptation & Rationale for Transition \\
\hline 3.1 .1 & Predictive model & $\begin{array}{l}\text { Differences exist in reimbursement structure } \\
\text { between Medicare and commercial plans and } \\
\text { even between commercial plans. An actuari- } \\
\text { ally sound model unique to each commercial } \\
\text { plan based on its data plus perhaps a national } \\
\text { benchmark should be considered. }\end{array}$ & $\begin{array}{l}\text { The particular model used in this study cannot } \\
\text { be used for other commercial data in a way that } \\
\text { is fair to providers. The CMS model is gener- } \\
\text { ated using a file of national Medicare data. This } \\
\text { model used data from the entire commercial } \\
\text { health plan as an alternative, since it should be } \\
\text { representative of the universe of patients and } \\
\text { physicians that would participate in oncology } \\
\text { episodes. CMS performed modeling on the } \\
\text { national data in order to choose a list of sig- } \\
\text { nificant covariates to include in the predictive } \\
\text { model. CMS included variables such as age, sex, } \\
\text { select noncancer comorbidities, and receipt of } \\
\text { bone marrow transplant. In this study, adminis- } \\
\text { trative medical claims were used. After analyzing } \\
\text { several years of data, only sex, age, cancer type, } \\
\text { and comorbidity index were included as the } \\
\text { covariates in the predictive model. Each health } \\
\text { plan would need to adapt actuarially developed } \\
\text { covariates. This study performed weighting in } \\
\text { the same manner as described in the OCM meth- } \\
\text { odology document. }\end{array}$ \\
\hline$\overline{3.2 .1}$ & Trend factor & $\begin{array}{l}\text { This model assumed participation of all } \\
\text { providers and this adjustment was not per- } \\
\text { formed; however, if there are nonparticipating } \\
\text { providers in an episode-based payment initia- } \\
\text { tive, covariates from the generalized linear } \\
\text { model can be applied to calculate the trend } \\
\text { factor as detailed in the OCM methodology } \\
\text { document. }\end{array}$ & $\begin{array}{l}\text { Nonparticipating providers do not exist for } \\
\text { purposes of this analysis and may not if a plan } \\
\text { forces all providers to participate in the OCM. If } \\
\text { it is decided that all practices must participate in } \\
\text { the episode-based payment model, this section } \\
\text { will not be applicable. }\end{array}$ \\
\hline 3.2 .2 & Novel therapy adjustment & $\begin{array}{l}\text { Individual plans must determine how to } \\
\text { handle novel therapies. }\end{array}$ & $\begin{array}{l}\text { If the drug meets criteria to be considered a new } \\
\text { agent and the proportion of the practice's new } \\
\text { drug expenditures to total expenditures is higher } \\
\text { than nonparticipating providers, the baseline } \\
\text { prices will be adjusted. If, in a commercial adap- } \\
\text { tation of OCM, the plan has nonparticipating } \\
\text { providers and has data for the providers, CMS } \\
\text { methodology may be used. }\end{array}$ \\
\hline
\end{tabular}

$\mathrm{CML}=$ chronic myelogenous leukemia; $C M S=$ Center for Medicare \& Medicaid Innovation; $C P T=$ Current Procedural Terminology; DMEPOS = Durable Medical Equipment, Prosthetics, Orthotics, and Supplies; EEM = evaluation and management; ESRD =end-stage renal disease; FDB =First Data Bank; GDCA=Gross Drug Cost above the Catastrophic; HHA = Home Health Agency; ID=identification; LICS=low-income cost-sharing subsidy; NA=not available; NCPDP=National Council for Prescription Drug Programs; NDC= National Drug Code; OCM= Oncology Care Model; SNF= skilled nursing facility. 